\title{
Sternotomy for aortic dissection with substernal pull through: The importance of surgical history
}

From the Department of Surgery, Yale University School of Medicine, New Haven, Conn.

Disclosures: Authors have nothing to disclose with regard to commercial support.

Received for publication Dec 18, 2018; revisions received March 24, 2019; accepted for publication April 12, 2019; available ahead of print July 23, 2019.

Address for reprints: Abeel A. Mangi, MD, Yale Physician's Building, 800 Howard Ave, 2nd Floor, New Haven, CT 06511 (E-mail: Abeel.Mangi@yale.edu).

J Thorac Cardiovasc Surg 2020;159:e325-6

$0022-5223 / \$ 36.00$

Copyright $(2019$ by The American Association for Thoracic Surgery

https://doi.org/10.1016/j.jtcvs.2019.04.038

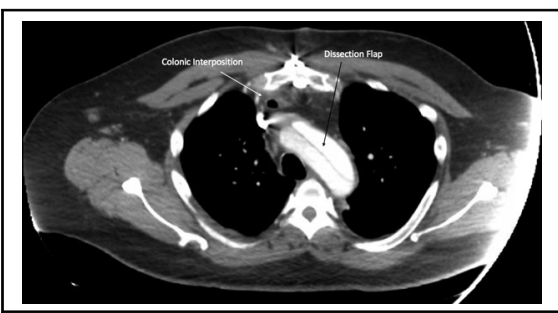

CTA depicts substernal colonic interposition graft with a type $\mathrm{A}$ aortic dissection.

\section{Central Message}

CTA of the chest in a 45-year-old man with a type A aortic dissection highlights the importance of thorough surgical history and preoperative imaging, even in an emergency setting.

See Commentary on page e327.
A 45-year-old man presented to the emergency department with chest pain and hypertension. Systolic blood pressures were asymmetric, with $180 \mathrm{~mm} \mathrm{Hg}$ in the left arm and $150 \mathrm{~mm} \mathrm{Hg}$ in the right arm. Computed tomographic angiography (CTA) of the chest suggested a type A aortic dissection originating in the aortic root and extending to the iliac bifurcation. The patient appeared grossly neurologically intact, without obvious signs of malperfusion. The patient's wife gave a history of lye ingestion as a toddler and subsequent esophagectomy. The CTA demonstrated the presence of a substernal colonic interposition graft (Figure 1 and Video 1). In the operating room, a sternotomy was performed with an oscillating saw. The conduit was not densely adherent and was mobilized from the sternum with a combination of sharp and blunt dissection, taking care to protect the mesentery. The colon was retracted into the right

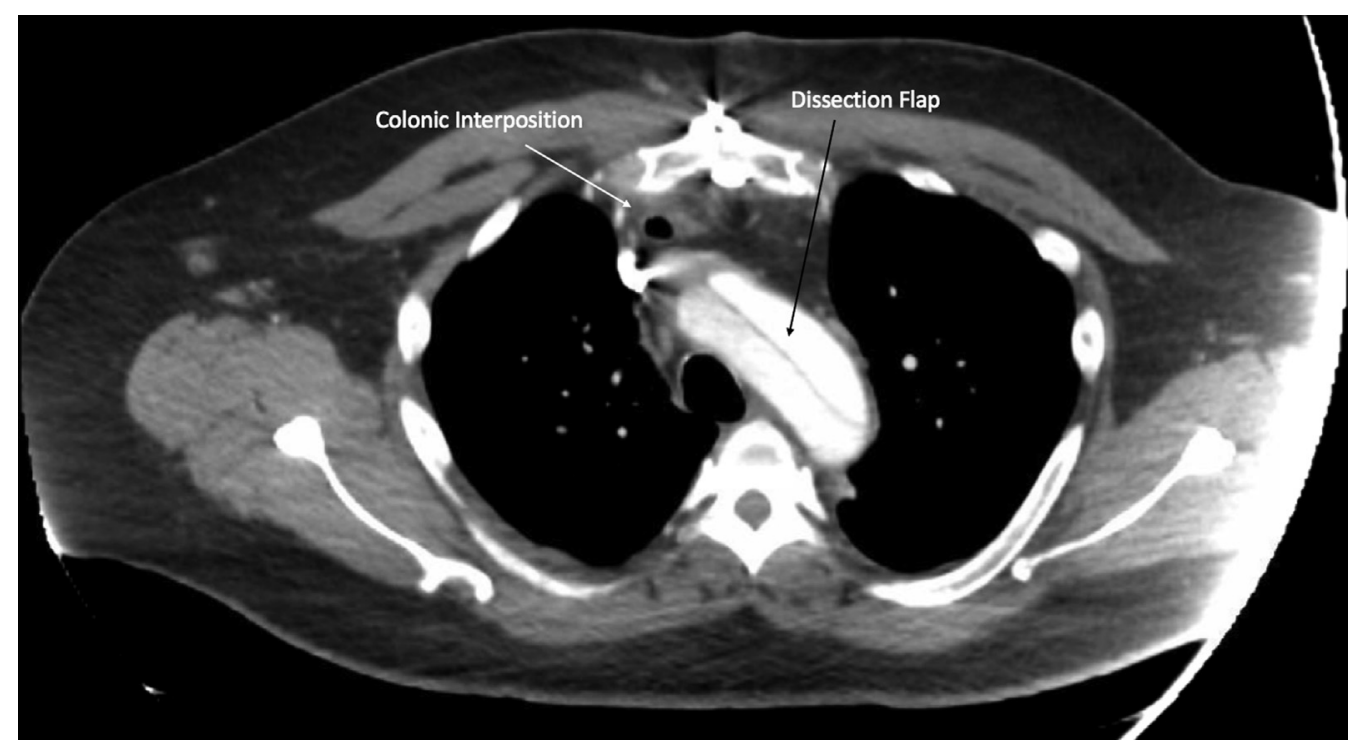

FIGURE 1. Computed tomography of the chest depicting a dissection flap traversing the aortic arch with the overlaid colonic interposition graft placed during childhood. 


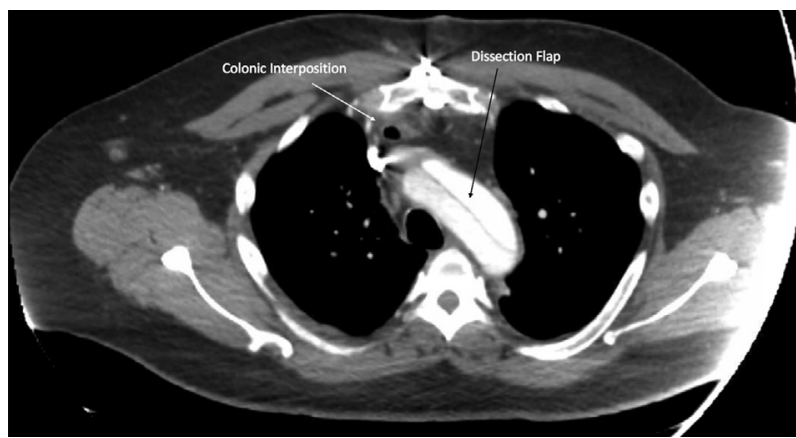

VIDEO 1. Description of a type A aortic dissection repair in an individual with a history of esophagectomy with gastric pull through. Video available at: https://www.jtcvs.org/article/S0022-5223(19)30934-1/fulltext.

pleural space, and a Bentall operation with replacement of the aortic root and reimplantation of coronary buttons to a valved conduit was performed. The patient was discharged home 13 days after the operation with the expectation of full recovery.

Of note, transesophageal echocardiography was not performed because of the history of esophagectomy, and preoperative transthoracic echocardiography could not identify the conduit. Had the colon been injured on entry, immediate containment of the stool content and repair of the injury would have been necessary. In addition to previous reports of this rare presentation, ${ }^{1,2}$ this case highlights the importance of obtaining a thorough history, including comorbidity, connective tissue disorders, and previous surgeries, to guide surgical planning, even in an emergency setting.

\section{References}

1. Vondran M, Bakhtiary F, Borger MA, Mohr FW. Acute type A aortic dissection surgery impeded by substernal colon interposition. Interact Cardiovasc Thorac Surg. 2015;20:146-7.

2. Kao CL, Lu MS, Chang JP. Acute type A intramural hematoma in a patient with substernal colon interposition. Tex Heart Inst J. 2011;38:454-5. 